\title{
Bilinguale Kinder lernen verzögert sprechen
}

\author{
Welchen Einfluss hat eine bilinguale Spracherziehung auf die Entwicklung der zwei Einzelsprachen? \\ Eine Studie aus den USA zeigt, dass zweisprachige Kinder den einsprachigen hinterherhinken.
}

_ Für eine prospektive Studie zur expressiven Sprachentwicklung im Alter von 30-60 Monaten wurden je 56 Mädchen und Jungen aus englisch und spanisch sprechenden Familien in Florida untersucht. Die Kontrollgruppe bildeten 39 Kinder, die nur englischsprachig aufwuchsen. Alle 6 Monate wurden Sprachenwicklungstests gemacht.

In beiden Gruppen war die Sprachentwicklung linear mit dem sozialen Status der Familie und dem Alter assoziiert. In der bilingualen Gruppe ergab sich ein exponenzieller Zusammenhang zwischen der Entwicklung der englischen Sprache und dem Zeitanteil, den das Englische im Familienleben hatte. Der Sprachgewinn im Spanischen verlief dagegen unabhängig von der Expositionsdauer linear. Auch verlief in dieser Gruppe die Entwicklungskurve für die englische Sprache wesentlich steiler. Mit 60 Monaten entsprach das expressive Sprachmuster bereits zu 51,8\% dem von Erwachsenen. Im Spanischen waren es hingegen nur $17,1 \%$. Die einsprachigen Kinder kamen zum selben Zeitpunkt allerdings sogar auf 73,5\%.

Insgesamt lagen die bilingualen Kinder - in Abhängigkeit von einigen Variablen wie dem sozialen Status - beim Erwerb der englischen Sprache 6-12 Monate hinter den einsprachigen Kindern.

- HoffE, Ribot KM. Language growth in English monolingual and Spanish-English bilingual children from 2,5 to 5 years. J Pediatr 2017, online 10. August; https://doi.org/10.1016/j.jpeds.2017.06.071

\section{KOMMENTAR}

Es überrascht, dass das Englische in den zweisprachigen Familien viel besser erlernt wurde als das Spanische. Das spricht dafür, dass die Sprachentwicklung nicht nur in der Familie erfolgt, sondern auch über außerfamiliäre Personen und Institutionen, in denen die jeweilige Landessprache gesprochen wird - z. B. Kindergärten. Das ist wichtig, wenn es um die Integration in ein Gesellschaftssystem geht, für die der Spracherwerb wesentlich ist. Hier ist nicht nur die Unterstützung der Familien etwa über ein Erziehungsgeld sinnvoll, sondern auch die Unterstützung bestimmter Institutionen, etwa Kindertagesstätten.

Prof. em. Dr. med. Dr. h.c. D. Reinhardt

\section{Ein Mittelfinger erlebt sein blaues Wunder}

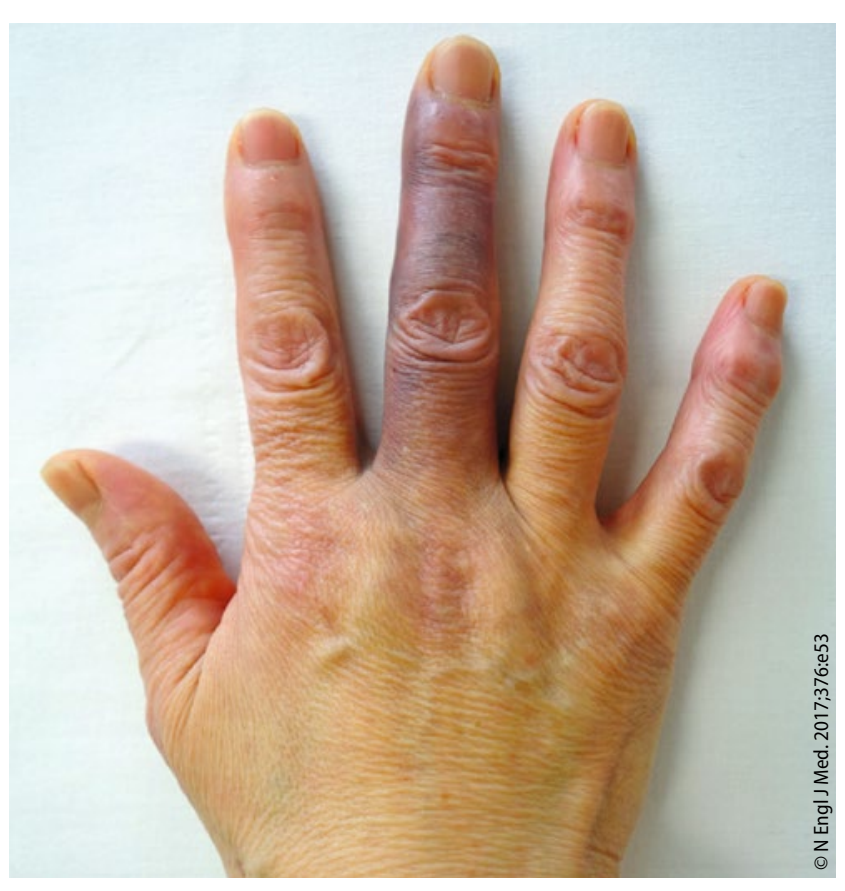

Blau verfärbter, schmerzender Mittelfinger.
Eine 66-jährige, bislang immer gesunde Frau stellte sich wegen plötzlich aufgetretener Schmerzen und einer Blauverfärbung des rechten Mittelfingers vor. Drei Wochen zuvor war bereits eine ähnliche Episode aufgetreten, die Symptomatik hatte sich damals innerhalb weniger Tage zurückgebildet. Die Frau konnte sich nicht an ein Trauma in der letzten Zeit erinnern. Auch stand sie unter keiner Dauermedikation. Der rechte Mittelfinger war durch ein subkutanes Hämatom angeschwollen, neurologische Ausfälle bestanden nicht. Beim Eintauchen in kaltes Wasser änderte sich die Farbe des Fingers nicht. Gerinnungsparameter und Plättchenzahl waren normal.

Man stellte die klinische Diagnose einer Finger-Apoplexie, auch bekannt als Achenbach-Syndrom. Es handelt sich dabei um eine plötzlich spontan auftretende, subkutane Blutung an Fingern oder Händen. Die Ursache der für die meisten betroffenen Patienten sehr beunruhigenden Veränderung ist unbekannt. Die wichtigste Aufgabe des Arztes besteht in Aufklärung und Beruhigung, da sich die Veränderungen praktisch immer von allein zurückbilden. So war es auch in diesem Fall. Eine Woche später sah der Mittelfinger wieder normal aus.

Prof. Dr. med. H. S. FüeßI

- Yamamoto Y, Yamamoto S. Achenbach's syndrome. N Engl J Med. 2017;376:e53 